\title{
ESCIMO.spread (v2): parameterization of a spreadsheet-based energy balance snow model for inside-canopy conditions
}

\author{
T. Marke ${ }^{1}$, E. Mair ${ }^{1}$, K. Förster ${ }^{1,3}$, F. Hanzer ${ }^{1,3}$, J. Garvelmann ${ }^{2}$, S. Pohl ${ }^{4}$, M. Warscher ${ }^{2}$, and U. Strasser ${ }^{1}$ \\ ${ }^{1}$ Institute of Geography, University of Innsbruck, Innsbruck, Austria \\ ${ }^{2}$ Institute of Meteorology and Climate Research (IMK-IFU), Karlsruhe Institute of Technology (KIT), \\ Garmisch-Partenkirchen, Germany \\ ${ }^{3}$ alpS - Centre for Climate Change Adaptation, Innsbruck, Austria \\ ${ }^{4}$ Hydrology Department, University of Freiburg, Freiburg, Germany \\ Correspondence to: T. Marke (thomas.marke@uibk.ac.at)
}

Received: 30 June 2015 - Published in Geosci. Model Dev. Discuss.: 25 September 2015

Revised: 19 January 2016 - Accepted: 20 January 2016 - Published: 16 February 2016

\begin{abstract}
This article describes the extension of the ESCIMO.spread spreadsheet-based point energy balance snow model by (i) an advanced approach for precipitation phase detection, (ii) a method for cold content and liquid water storage consideration and (iii) a canopy sub-model that allows the quantification of canopy effects on the meteorological conditions inside the forest as well as the simulation of snow accumulation and ablation inside a forest stand. To provide the data for model application and evaluation, innovative low-cost snow monitoring systems (SnoMoS) have been utilized that allow the collection of important meteorological and snow information inside and outside the canopy. The model performance with respect to both, the modification of meteorological conditions as well as the subsequent calculation of the snow cover evolution, are evaluated using insideand outside-canopy observations of meteorological variables and snow cover evolution as provided by a pair of SnoMoS for a site in the Black Forest mountain range (southwestern Germany). The validation results for the simulated snow water equivalent with Nash-Sutcliffe model efficiency values of 0.81 and 0.71 and root mean square errors of 8.26 and $18.07 \mathrm{~mm}$ indicate a good overall model performance inside and outside the forest canopy, respectively. The newly developed version of the model referred to as ESCIMO.spread (v2) is provided free of charge together with 1 year of sample data including the meteorological data and snow observations used in this study.
\end{abstract}

\section{Introduction}

In forested areas significant variations in snow accumulation can result from the processes of forest canopy interception and sublimation of intercepted snow (Marsh, 1999; Pomeroy et al., 1998). Snowfall in forested areas is either intercepted by stems, needles and branches or passes through the canopy, directly reaching the underlying forest floor. Due to its large surface area exposed to the surrounding atmosphere, intercepted snow can be subject to high sublimation losses, especially in dry continental climates. Generally, sublimation losses of previously intercepted snow can be as high as $30 \%$ of snow precipitation, depending on the efficiency of interception, its duration and the atmospheric boundary conditions (Liston and Elder, 2006b; Pomeroy and Gray, 1995; Strasser et al., 2008). Intercepted snow can also be removed from the canopy by direct unloading and dripping of meltwater to the ground (Liston and Elder, 2006b; Pomeroy et al., 2002). Compared to snow in the open, snow in forest canopies is exposed to different meteorological conditions. It is sheltered from wind and incoming shortwave radiation while receiving increased longwave radiation emitted from the surrounding trees (Link and Marks, 1999a, b). Likewise, humidity and temperature underneath a canopy differ from those in the open (Liston and Elder, 2006b). In the boundary layer, forest canopies moreover strongly modify the interactions between snow-covered surfaces and the atmosphere. Even the litter on the forest floor has a significant effect on 
the radiative properties of the snow cover beneath a canopy (Melloh et al., 2002; Hardy et al., 2001).

The influences of a forest canopy on the snow cover dynamics beneath are very complex. The snow cover duration in the forest depends on various factors. A delay of the spring snowmelt under a dense forest canopy compared to open areas due to the reduction of incoming solar radiation was shown by Link and Marks (1999a). On the other hand, shorter snowpack duration in the forest was observed by Dickerson-Lange et al. (2015). Strasser et al. (2011) showed in a numerical modeling experiment for a virtual mountain that in snow-rich winters, the shadowing and its protective effect are dominant. In winters with little snow, snow sublimation losses become dominant and, consequently, the snow lasts longer in the open than inside the forest, mainly for northern exposures (in the Northern Hemisphere). Similar patterns were observed by Pohl et al. (2014) in the Black Forest region.

To develop a free and easy-to-use tool for the simulation of the temporal evolution of the snow cover with explicit consideration of these complex snow-canopy-atmosphere interactions, the ESCIMO.spread spreadsheet-based point energy balance snow model developed by Strasser and Marke (2010) (in the following referred to as ESCIMO.spread (v1)) has been extended with a canopy sub-model. Moreover, the model has been improved by integrating an advanced algorithm for precipitation phase detection that applies wet-bulb temperature as a criterion to distinguish solid and liquid precipitation. Another model improvement is a new parameterization for cold and liquid water content of the snow cover allowing the consideration of refreezing of liquid precipitation or meltwater in the snowpack. Compared to other existing spreadsheet-based snow models (e.g., the glacier and snowmelt study model by Brock and Arnold, 2000), ESCIMO.spread (v2) is particularly fast and can easily be modified by a simple change of the parameters and formulae with results immediately visualized. With hourly recordings of temperature, precipitation, wind speed, relative humidity and global as well as longwave radiation, the model's demand on meteorological input is covered by those variables most commonly recorded at any state-of-the-art automatic weather station. While Walter et al. (2005) have presented a spreadsheet energy balance model that requires even fewer meteorological input data (daily minimum/maximum temperature and precipitation), their approach operates at a daily time step only and does not allow a quantification of subdaily variations in snow cover conditions. Moreover, compared to the canopy model implemented in ESCIMO.spread (v2), the consideration of canopy effects in the Walter et al. (2005) model is reduced to a canopy-induced extinction of solar radiation only. Canopy effects on other meteorological variables or vegetation-snow cover interactions (e.g., the interception of snow in the canopy) are not accounted for. By providing the option to define trends in precipitation and/or temperature in the model's parameter section, ES-
CIMO.spread allows the calculation of sensitivity tests for changes in temperature and precipitation for any site of interest. As ESCIMO.spread (v2) is in simple table format and does not include any macros, it can be applied by all common spreadsheet programs (e.g., Microsoft Excel, Apple Numbers, OpenOffice Calc) on a variety of platforms (Windows, Linux, Mac OS). Due to its simplicity, ESCIMO.spread (v2) is particularly suitable for application in education (e.g., in practically oriented student courses) and can even be operated with laptop computers, e.g., to visualize and make plausible measured meteorological parameters and the simulated snow cover directly in the field.

With its new features of

- sophisticated precipitation phase detection using a wetbulb temperature threshold,

- snow temperature estimation,

- cold content and liquid water content calculation with consideration of refreezing of water from melt or liquid precipitation, and meltwater outflow,

- transformation of standard meteorological observations (precipitation, relative humidity, temperature, wind speed, global radiation) from the open into conditions inside a forest canopy,

- calculation of snow interception and subsequent sublimation, melt or dropping of intercepted snow to the ground, and

- calculation of the beneath-canopy snow energy and mass balance,

the new version ESCIMO.spread (v2) reaches beyond the capabilities of most other freely available point-scale spreadsheet-based snow models and can be expected to set forth the history of ESCIMO.spread as a well-accepted, documented and freely available snow model for application in both science and education. This paper describes the newly implemented algorithms and evaluates the model results against available hydrometeorological observations inside and outside the forest canopy at a site in the Black Forest mountain range (southwestern Germany; see Fig. 1) with a mostly temperate snow cover at an elevation of $800 \mathrm{~m}$ a.s.l. The applied hydrometeorological data have been recorded by a set of low-cost snow monitoring systems (SnoMoS) recently developed by Pohl et al. (2014). The model can be downloaded from www.alpinehydroclimatology.net together with 1 year of example meteorological recordings and snow observations. 


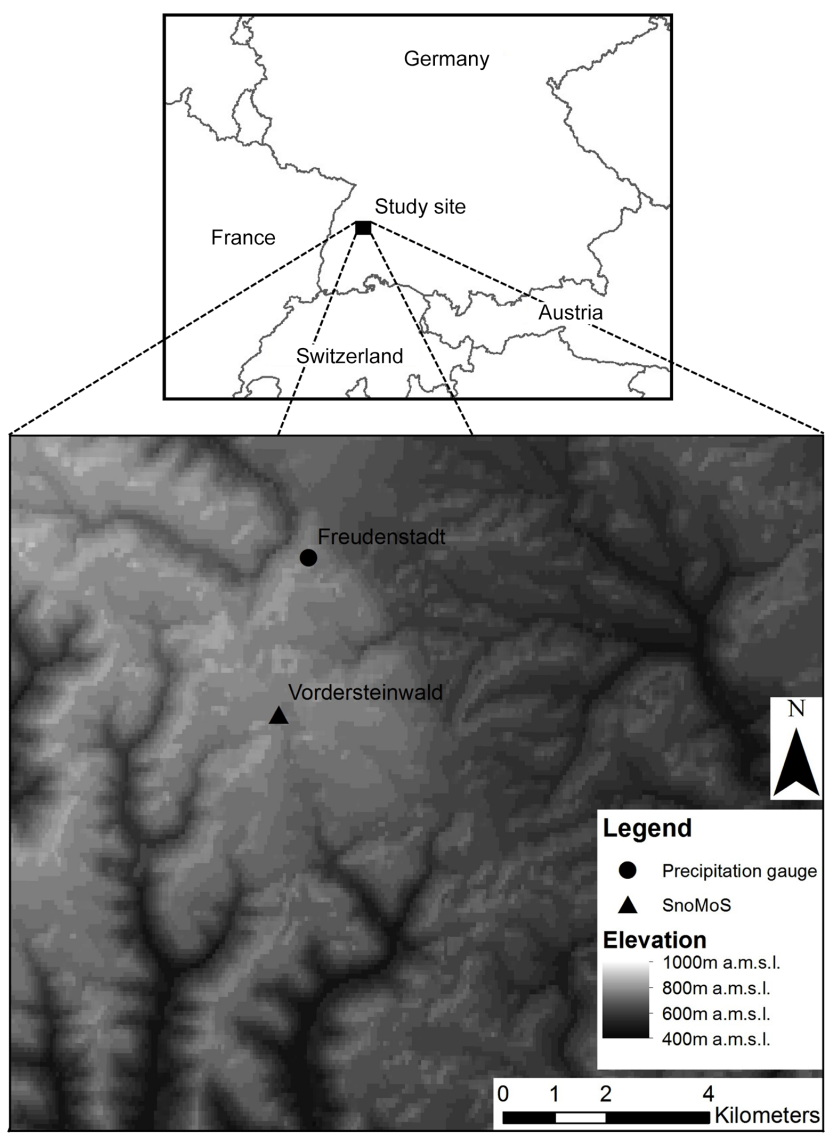

Figure 1. The Vordersteinwald site in the Black Forest mountain range (southwestern Germany, $800 \mathrm{~m}$ a.s.1.).

\section{The ESCIMO.spread model (v2)}

\subsection{General description}

The new version of ESCIMO.spread (v2) builds upon the ESCIMO.spread model as published by Strasser and Marke (2010). It is a 1-D, one-layer process model that calculates snow accumulation and melt for a snow cover assumed to be a single and homogeneous pack. To do so, it solves the energy and mass balance equations for the snow surface applying simple parameterizations of the relevant processes. The energy balance of the snow surface is calculated for each hourly time step considering shortwave and longwave radiation, sensible and latent heat fluxes, energy conducted by solid or liquid precipitation, as well as sublimation/resublimation and a constant soil heat flux (Strasser and Marke, 2010). Thereby, absorbed and reflected shortwave radiation is calculated from incoming shortwave radiation on the basis of the snow albedo, which is estimated for each hourly time step using an albedo ageing curve approach. Solid precipitation increases the amount of snow water equivalent (SWE) on the land surface, while liquid precipitation is (up to a certain maximum amount depending on ac-

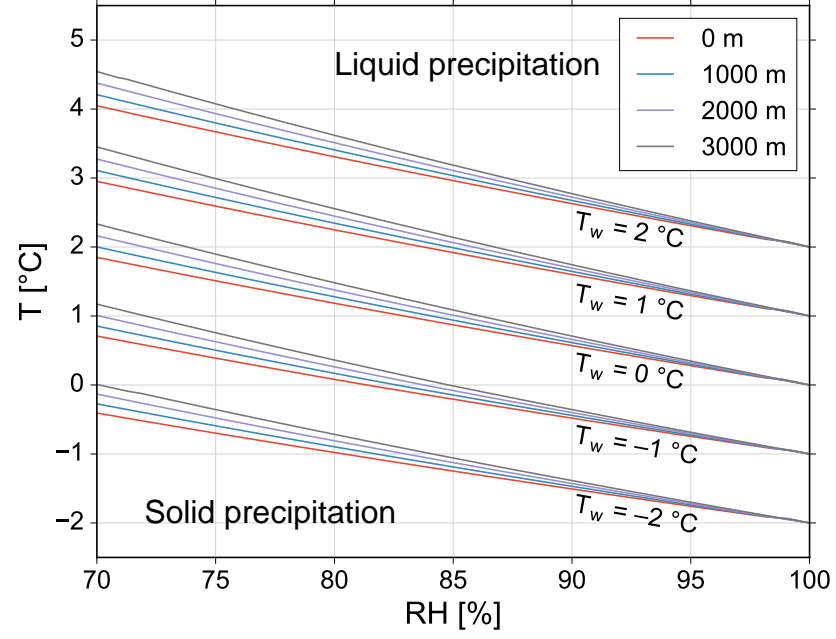

Figure 2. Relation between air temperature, wet-bulb temperature and relative humidity at different altitudes. The latter represent different air pressure levels derived using the hydrostatic equation. The colored lines can be interpreted as borderlines to separate liquid and solid precipitation assuming a certain threshold wet-bulb temperature.

tual SWE) added to the liquid water storage of the snowpack. While melt in ESCIMO.spread (v1) has been calculated from the energy balance remainder only if air temperature exceeds 273.16 K, the newly implemented method for snow temperature estimation (see Sect. 2.3) allows the removal of this condition in ESCIMO.spread (v2). The model results are visualized in the form of diagrams for the majority of model variables, together with four quantitative measures of goodness of fit.

\subsection{Precipitation phase detection}

The new version of ESCIMO.spread (v2) includes an improved distinction between liquid and solid precipitation. As air temperature $T_{\mathrm{a}}$ is often an insufficient indicator of the precipitation water phase (Steinacker, 1983), wet-bulb temperature $T_{\mathrm{w}}$ is used in ESCIMO.spread (v2) as a combined measure of air temperature and humidity to distinguish liquid from solid precipitation. Figure 2 shows the relation between air temperature, wet-bulb temperature and relative humidity for different altitudes to account for the dependence of wet-bulb temperature on air pressure. Each of the displayed lines in Fig. 2 could be interpreted as a borderline to separate liquid and solid precipitation assuming a certain threshold wet-bulb temperature. The largest differences between air temperature and wet-bulb temperature occur at low air humidities, clearly pronouncing the added value associated with application of wet-bulb temperature as a criterion for phase detection. 
Generally, wet-bulb temperature can be derived by solving the psychrometric equation

$e_{\mathrm{a}}\left(T_{\mathrm{a}}\right)-e_{\mathrm{s}}\left(T_{\mathrm{w}}\right)-A \cdot\left(T_{\mathrm{a}}-T_{\mathrm{w}}\right)=0$

for $T_{\mathrm{w}}(\mathrm{K})$, where $A\left(\mathrm{~Pa} \mathrm{~K}^{-1}\right)$ is the psychrometric constant, and $e_{\mathrm{a}}\left(T_{\mathrm{w}}\right)(\mathrm{Pa})$ and $e_{\mathrm{S}}\left(T_{\mathrm{w}}\right)(\mathrm{Pa})$ the vapor pressure of the air and the saturation vapor pressure at wet-bulb temperature, respectively. As there is no explicit solution to the psychrometric equation (Campbell and Norman, 1998) and iterations are unfavorable in a spreadsheet model, a pragmatic assumption has been made: for a broad range of combinations of air temperature and relative humidity values, lookup tables have been generated outside the spreadsheet model using an iterative solution scheme for Eq. (1). Beside temperature and humidity, wet-bulb temperature also depends on air pressure $p_{z}(\mathrm{~Pa})$ that is required to calculate the psychrometric constant, $A$, as (Kraus, 2004)

$A=\frac{p_{z} \cdot c_{p}}{0.622 \cdot L_{\mathrm{v}}}$,

where $c_{p}$ is the specific heat capacity of air at constant pressure $\left(1004 \mathrm{~J} \mathrm{~kg}^{-1} \mathrm{~K}^{-1}\right)$ and $L_{\mathrm{V}}\left(\mathrm{J} \mathrm{kg}^{-1}\right)$ represents the latent heat of vaporization. In ESCIMO.spread (v2) the temperature dependence of the psychrometric constant is neglected since this dependency is by far less important compared to that associated with air pressure at higher altitudes (Kraus, 2004; Campbell and Norman, 1998). Air pressure, $p(\mathrm{~Pa})$, at a given elevation, $z(\mathrm{~m})$, can be derived from standard atmospheric pressure, $p_{0}(\mathrm{~Pa})$, by integration of the hydrostatic equation assuming a linear decrease in temperature with increasing altitude $\left(\gamma=-0.0065 \mathrm{~K} \mathrm{~m}^{-1}\right)$

$p_{z}=p_{0}\left[\frac{T_{\mathrm{a}}}{T_{\mathrm{a}}-\gamma \cdot z}\right]^{-\frac{g}{\gamma \cdot R}}$,

where $R$ is the gas constant of dry air $\left(287 \mathrm{~J} \mathrm{~kg}^{-1} \mathrm{~K}^{-1}\right)$ and $g$ is gravity $\left(\mathrm{m} \mathrm{s}^{-2}\right)$. To account for the air pressure dependence, the implemented lookup tables have been prepared for several elevation bands with a $500 \mathrm{~m}$ interval. Figure 3 shows a comparison of wet-bulb temperatures calculated using the lookup table approach to those achieved with an iterative solution for different elevations. The differences between both approaches shown for a common snowfall situation are relatively small. Therefore, the lookup table approach allows a sufficiently accurate estimation of wet-bulb temperature in the model. The threshold for wet-bulb temperature as required for precipitation phase detection in ESCIMO.spread (v2) is one of the user-defined input parameters and is here set to $273.16 \mathrm{~K}$. To avoid sudden changes in precipitation phase when temperatures fall below the defined temperature threshold, in ESCIMO.spread (v2) a temperature range can be defined (e.g., $273.16 \pm 0.5 \mathrm{~K}$ ) in which liquid precipitation decreases from 100 to $0 \%$ with solid precipitation increasing accordingly. When temperature is exactly at the defined temperature threshold (here $273.16 \mathrm{~K}$ ), this approach results in $50 \%$ liquid and $50 \%$ solid precipitation.

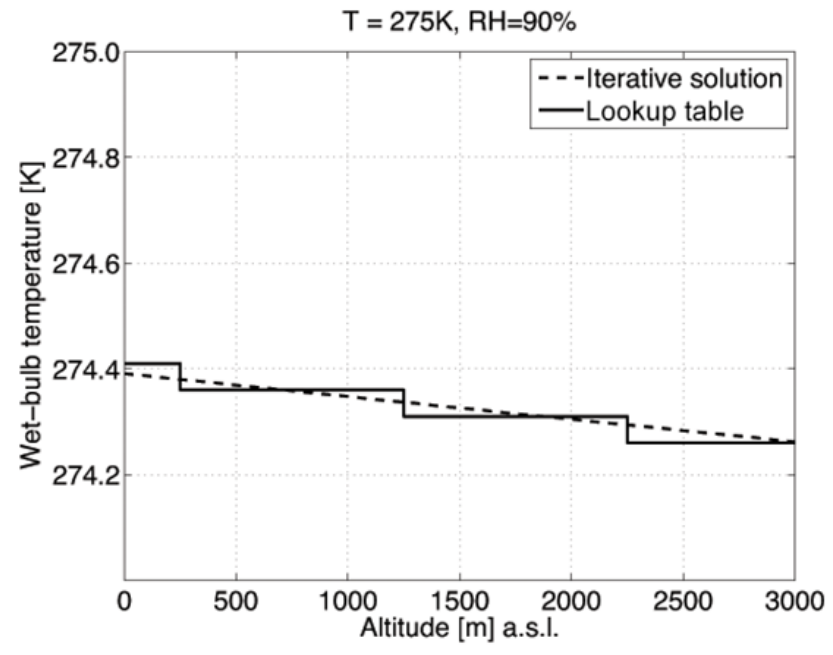

Figure 3. Comparison of iteratively calculated wet-bulb temperature to the results of the lookup table approach implemented in ESCIMO.spread (v2).

\subsection{Cold and liquid water content}

A physically based method for estimating the snow temperature and deriving the cold content of a single-layer snowpack has been implemented in ESCIMO.spread (v2) following an approach presented by Walter et al. (2005). The snow temperature $T_{\mathrm{S}}(\mathrm{K})$ for a given time step is derived using the snow temperature calculated for the previous time step, $T_{\mathrm{s} t-1}(\mathrm{~K})$, and a temperature change $\mathrm{d} T(\mathrm{~K})$ as

$T_{\mathrm{s}}=\min \left\{T_{\mathrm{s} t-1}+\mathrm{d} T, 273.16\right\}$.

The temperature change in Eq. (4) is derived as

$\mathrm{d} T=\frac{E_{t-1} \cdot \mathrm{d} t+\mathrm{RF}_{t-1} \cdot c_{\mathrm{i}}}{\left(\mathrm{SWE}_{t-1}+P_{\mathrm{s}}\right) \cdot c_{\mathrm{s}}}$,

where $E_{t-1}\left(\mathrm{~W} \mathrm{~m}^{-2}\right)$ is the energy balance of the previous time step, $\mathrm{d} t(\mathrm{~s})$ is the time step length, $\mathrm{RF}_{t-1}(\mathrm{~mm})$ is the liquid water refrozen in the previous time step, $c_{\mathrm{i}}$ is the melting heat of ice $\left(3.337 \times 10^{5} \mathrm{~J} \mathrm{~kg}^{-1}\right), \mathrm{SWE}_{t-1}(\mathrm{~mm})$ is the SWE of the previous time step, $P_{\mathrm{S}}(\mathrm{mm})$ is the solid precipitation in the current time step and $c_{\mathrm{S}}$ is the specific heat of snow $\left(2100 \mathrm{~J} \mathrm{~kg}^{-1} \mathrm{~K}^{-1}\right)$.

Using this approach, heat losses resulting from a negative energy balance can be used to build up a cold content, which represents the amount of energy required to increase snow temperature to $273.16 \mathrm{~K}$. Snow temperature and cold content can be considered as equivalent and physically consistent representations of the snowpack's energy state as defined by Eq. (6). The cold content first needs to be reduced to zero by positive energy inputs before actual melt can occur. By implementing a concept for liquid water content as proposed by Braun (1984) and Blöschl and Kirnbauer (1991), melting snow is not immediately removed from the snowpack, but 
a certain amount of liquid water can be retained (and possibly refreeze again). Combining these approaches for cold content estimation and liquid water content accounts for the delay between beginning surface melt and drainage of a snow cover.

The cold content $C_{\mathrm{c}}(\mathrm{mm})$ for each model time step is inferred directly from calculated snow temperature in the form of

$C_{\mathrm{c}}=\frac{\left(T_{\mathrm{s}}-273.16\right) \cdot\left(\mathrm{SWE}_{t-1}+P_{\mathrm{s}}\right) \cdot c_{\mathrm{s}}}{c_{\mathrm{i}}}$.

In the case of a negative energy balance, a refreezing of liquid water in the snowpack, RF ( $\mathrm{mm})$, is calculated in the form of

$\mathrm{RF}=\min \left\{C_{\mathrm{lw} t-1},(-E \cdot \mathrm{d} t) / c_{\mathrm{i}}\right\}$,

where $C_{\mathrm{lw} t-1}(\mathrm{~mm})$ is the liquid water content of the previous time step. $C_{\mathrm{lw}}$ for a given time step can be derived as

$C_{\mathrm{lw}}=C_{\mathrm{lw} t-1}+P_{1}-\mathrm{RF}$,

where $P_{1}(\mathrm{~mm})$ is liquid precipitation.

In the case of a positive energy balance, actual melt, $M$ $(\mathrm{mm})$, is calculated considering the change in cold content between the current and previous time step as

$M=\min \left\{\left(E \cdot \mathrm{d} t / c_{\mathrm{i}}\right)-\left(C_{\mathrm{c}}-C_{\mathrm{c} t-1}\right)\right.$,

$\left.\left(\mathrm{SWE}_{t-1}-C_{\mathrm{c} t-1}\right)\right\}$.

$C_{\mathrm{lw}}$ is then updated in the form of

$C_{\mathrm{lw}}=\min \left\{C_{\mathrm{lw} t-1}+M, \mathrm{SWE}_{t-1} \cdot \mathrm{HC}_{\mathrm{w}}\right\}$,

where $\mathrm{HC}_{\mathrm{w}}(-)$ is a water holding capacity that limits liquid water storage and is specified as a fraction of the total snowpack weight. This parameter is to be defined by the user in the model's parameter section and set to $\mathrm{HC}_{\mathrm{w}}=0.1$ as recommended by Blöschl and Kirnbauer (1991) by default.

Finally, the outflow (i.e., the excess water that is actually removed from the snowpack), $O(\mathrm{~mm})$, can be calculated as

$O=\max \left\{\left(C_{\mathrm{lw} t-1}+P_{1}+M\right)-\mathrm{SWE}_{t-1} \cdot \mathrm{HC}_{\mathrm{w}}, 0\right\}$.

\subsection{Modification of meteorological conditions inside the forest canopy}

The canopy model newly implemented in ESCIMO.spread (v2) by Liston and Elder (2006b) has already been successfully applied under alpine conditions (see Strasser, 2008, or Strasser et al., 2011). The development of the approach was motivated by the fact that meteorological observations inside forest canopies only sparsely exist, necessitating the estimation of inside-canopy conditions from available meteorological observations in the open. The method requires information on leaf area index and canopy height that can either be derived from field measurements or be taken from the literature for a wide range of plant species (e.g., from Breuer et al., 2003, or Liston and Elder, 2006b).

Wind speed inside the canopy $u_{\mathrm{c}}\left(\mathrm{m} \mathrm{s}^{-1}\right)$ is derived from above-canopy wind speed $u\left(\mathrm{~m} \mathrm{~s}^{-1}\right)$ as (Cionco, 1978)

$u_{\mathrm{c}}=u \exp (-a \cdot(1-z / h))$,

where $h(\mathrm{~m})$ is the canopy height and $z(\mathrm{~m})$ is the canopy reference level assumed to be $0.6 \mathrm{~h}$ (Liston and Elder, 2006b; Essery et al., 2003).

The canopy flow index, $a(-)$, is calculated as a function of the effective leaf area index LAI* $\left(\mathrm{m}^{2} \mathrm{~m}^{-2}\right)$ and a scaling factor, $\beta(=0.9)$, that is introduced by Liston and Elder (2006b) to make $\mathrm{LAI}^{*}$ compatible with the canopy flow index proposed by Cionco (1978):

$a=\mathrm{LAI}^{*} \cdot \beta$.

$\mathrm{LAI}^{*}$ includes stems, leaves and branches as described by Chen et al. (1997).

To consider the extinction of solar radiation by the forest canopy, top-of-canopy incoming shortwave radiation, $Q_{\mathrm{si}}$, is reduced following the Beer-Lambert law as

$Q_{\text {sif }}=Q_{\mathrm{si}} \cdot \tau_{\mathrm{v}}$,

where $Q_{\text {sif }}$ is the incoming shortwave radiation impinging on the snow surface beneath the canopy (Hellström, 2001). $\tau_{\mathrm{v}}$ representing the fraction of $Q_{\mathrm{si}}$ reaching the land surface is derived as

$\tau_{\mathrm{v}}=\exp \left(-k \cdot \mathrm{LAI}^{*}\right)$,

with $k$ being a vegetation-dependent extinction coefficient (Liston and Elder, 2006b). Aiming at a best fit to observed radiation inside forest canopies of different species (e.g., spruce, subalpine fir, pine) at a site in the U.S. Department of Agriculture (USDA) Fraser Experimental Forest near Fraser (Colorado, USA), Liston and Elder (2006b) have yielded the best overall performance using a $k$ value of 0.71 , which is also used for the simulations here.

Incoming longwave radiation inside the canopy is assumed to be composed of a fraction $F_{\mathrm{g}}(-)$ directly reaching the ground through gaps in the forest stand and a fraction $F_{\mathrm{c}}(-)$ emitted by the forest canopy. The canopy-emitted fraction is calculated following Liston and Elder (2006a) as

$F_{\mathrm{c}}=a+b \cdot \ln \left(\mathrm{LAI}^{*}\right)$,

where $a(-)$ and $b(-)$ are constants with values of 0.55 and 0.29 , respectively. A value of $F_{\mathrm{g}}$ can be derived as

$F_{\mathrm{g}}=1-F_{\mathrm{c}}$,

with both calculated fractions used to estimate inside-canopy incoming longwave radiation $Q_{\text {lif }}\left(\mathrm{W} \mathrm{m}^{-2}\right)$ from

$Q_{\text {lif }}=\left(F_{\mathrm{g}} \cdot Q_{\mathrm{li}}\right)+\left(F_{\mathrm{c}} \cdot \sigma \cdot T_{\mathrm{c}}^{4}\right)$, 
where $Q_{\mathrm{li}}\left(\mathrm{W} \mathrm{m}^{-2}\right)$ represents the top-of-canopy incoming longwave radiation. The latter is provided as input for ESCIMO.spread (v2) and is here estimated as a function of temperature and cloud cover as proposed by Liston and Elder (2006a) due to a lack of observations. $\sigma$ represents the Stefan-Boltzmann constant and $T_{\mathrm{c}}(\mathrm{K})$ the inside-canopy temperature. Assuming a linear dependency on canopy fraction, $T_{\mathrm{c}}$ is derived from top-of-canopy temperature $T_{\mathrm{a}}(\mathrm{K})$ as proposed by Obled (1971):

$T_{\mathrm{c}}=T_{\mathrm{a}}-F_{\mathrm{c}}$.

$\left(T_{\mathrm{a}}-\left(R_{\mathrm{c}} \cdot\left(T_{\mathrm{a}}-T_{\text {mean }}\right)+T_{\text {mean }}-\delta T\right)\right)$,

where $T_{\text {mean }}(\mathrm{K})$ is the mean daily air temperature, $R_{\mathrm{c}}(-)$ is a dimensionless scaling parameter set to 0.8 and $\delta T(-2 \mathrm{~K} \leq$ $\delta T \leq+2 \mathrm{~K}$ ) is a temperature offset defined as (Durot, 1999)

$\delta T=\frac{T_{\text {mean }}-273.16}{3}$.

Durot (1999) has further shown that relative humidity inside the canopy, $\mathrm{RH}_{\mathrm{c}}(\%)$, is often higher compared to the open due to sublimation and evaporation of melted snow. We therefore propose to modify top-of-canopy humidity RH (\%) with consideration of the canopy fraction in the form of (Durot, 1999)

$\mathrm{RH}_{\mathrm{c}}=\max \left\{\mathrm{RH} \cdot\left(1+0.1 \cdot F_{\mathrm{c}}\right), 100\right\}$.

\subsection{Simulating canopy effects on the snow cover}

The following describes the newly implemented approaches to describe snow interception through the forest canopy as well as melt-induced unloading of intercepted snow from the canopy.

Interception of solid precipitation $P_{\mathrm{S}}(\mathrm{mm})$ at time $t$ is derived introducing a canopy-intercepted load, $I(\mathrm{~mm})$, expressed as (Pomeroy et al., 1998)

$I=I_{t-1}+0.7 \cdot\left(I_{\max }-I_{t-1}\right) \cdot\left(1-\exp \left(-P_{\mathrm{s}} / I_{\max }\right)\right)$,

where $t-1$ represents the previous time step and $I_{\max }$ is the maximum interception storage calculated as (Hedstrom and Pomeroy, 1998)

$I_{\max }=4.4 \cdot \mathrm{LAI}^{*}$.

Sublimation of intercepted snow $Q_{\mathrm{cs}}(\mathrm{mm})$ is calculated as described by Liston and Elder (2006b) as

$Q_{\mathrm{cs}}=C_{\mathrm{e}} \cdot I \cdot \Psi_{\mathrm{s}} \cdot \mathrm{d} t$

where $\mathrm{d} t(\mathrm{~s})$ is the time increment (here: $3600 \mathrm{~s}), \Psi_{\mathrm{s}}\left(\mathrm{s}^{-1}\right)$ is the sublimation-loss rate coefficient for an ice sphere and $C_{\mathrm{e}}(-)$ represents the canopy exposure coefficient. Ice spheres are assumed to be characterized by a constant radius of $500 \mu \mathrm{m}$ as proposed by Liston and Elder (2006b).
The canopy exposure coefficient is calculated as

$C_{\mathrm{e}}=k_{\mathrm{c}} \cdot\left(I / I_{\max }\right)^{-0.4}$,

where $k_{\mathrm{c}}(-)$ is a dimensionless coefficient related to the shape of the intercepted snow deposits (Liston and Elder, 2006b). Sublimation at the canopy scale is hence estimated based on sublimation from individual ice spheres. Analyzing observed (Montesi et al., 2004) and modeled sublimation rates for a $2.7 \mathrm{~m}$ tall subalpine fir tree at the USDA Fraser Experimental Forest, Liston and Elder (2006b) have found that the application of $k_{\mathrm{c}}=0.010$ seems to best reproduce observed sublimation rates at both, higher and lower elevated tree sites. This value is very close to the value of $k_{\mathrm{c}}=0.011$ derived by Pomeroy et al. (1998) for the Canadian boreal forest and is used as the $k_{\mathrm{c}}$ value for the calculations with ECIMO.spread (v2) here. This parameter can be easily adapted by changing the respective setting in the parameter section of the model.

The sublimation-loss rate coefficient $\Psi_{\mathrm{s}}$ is calculated from the particle mass $m(\mathrm{~kg})$ in the form of

$\Psi_{\mathrm{s}}=(\mathrm{d} m / \mathrm{d} t) / m$,

where the particle mass is given by

$m=\frac{3}{4} \cdot \pi \cdot \rho_{\mathrm{i}} \cdot r^{3}$,

with $\rho_{\mathrm{i}}\left(\mathrm{kg} \mathrm{m}^{-3}\right)$ being ice density and $r(\mathrm{~m})$ representing the radius of a spherical ice particle (assumed to be $500 \mu \mathrm{m}$ as proposed by Liston and Elder, 2006b).

Mass loss from an ice particle is described as a function of intercepted solar radiation, humidity gradients between the ice surface and the surrounding atmosphere, the size of the considered ice particle and a ventilation term, following Thorpe and Mason (1966) and Schmidt (1972):

$\frac{\mathrm{d} m}{\mathrm{~d} t}=\frac{2 \cdot \pi\left(\frac{\mathrm{RH}}{100}\right)-S_{\mathrm{p}} \cdot \Omega}{h_{\mathrm{s}} \cdot \Omega+\frac{1}{D \cdot \rho_{\mathrm{v}} \cdot S \cdot h}}$,

where $h_{\mathrm{S}}$ is the latent heat of sublimation $(2.8355 \times$ $\left.10^{6} \mathrm{~J} \mathrm{~kg}^{-1}\right)$.

The diffusivity of water vapor in the atmosphere, $D$ $\left(\mathrm{m}^{2} \mathrm{~s}^{-1}\right)$, is derived following Thorpe and Mason (1966) as

$D=2.06 \times 10^{-5}\left(T_{\mathrm{a}} / 273\right)^{1.75}$.

The molecular weight of water $M\left(18.01 \mathrm{~kg} \mathrm{kmole}^{-1}\right)$, the universal gas constant $R\left(8313 \mathrm{~J} \mathrm{kmole}^{-1} \mathrm{~K}^{-1}\right)$, air temperature $T_{\mathrm{a}}(\mathrm{K})$ and the thermal conductivity of the atmosphere $\lambda_{\mathrm{t}}\left(0.024 \mathrm{~J} \mathrm{~m}^{-1} \mathrm{~s}^{-1} \mathrm{~K}^{-1}\right)$ are used to calculate $\Omega$ as proposed by Liston and Elder (2006b):

$\Omega=\frac{1}{\lambda_{\mathrm{t}} \cdot T_{\mathrm{a}} \cdot N u} \cdot\left(\frac{h_{\mathrm{s}} \cdot M}{R \cdot T_{\mathrm{a}}}-1\right)$. 


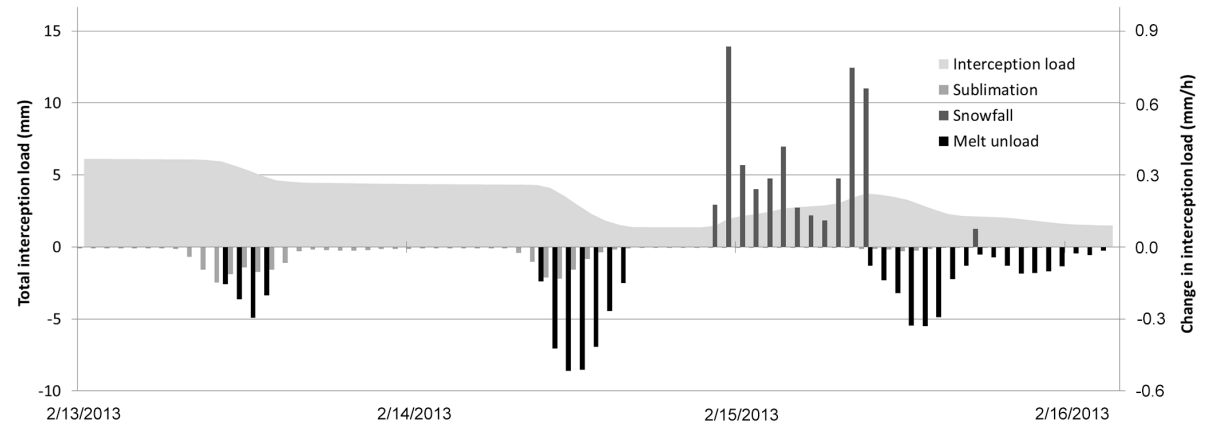

Figure 4. Simulated filling and depletion of the interception storage through snowfall, sublimation and melt-induced unload at site Vordersteinwald in the Black Forest mountain range (southwestern Germany).

The Nusselt number $\mathrm{Nu}$ and Sherwood number $\mathrm{Sh}$ are both calculated as

$N u=S h=1.79+0.606 \cdot R e^{0.5}$,

where $\operatorname{Re}(0.7<\operatorname{Re}<10)$ is the Reynolds number expressed by

$R e=\frac{2 \cdot r \cdot u_{\mathrm{c}}}{v}$

with $v$ representing the kinematic viscosity of air (1.3. $10^{-5} \mathrm{~m}^{2} \mathrm{~s}^{-1}$ ) and $u_{\mathrm{c}}$ the ventilation velocity inside the canopy, which is set equal to inside-canopy wind speed as proposed by Liston and Elder (2006b).

Following Fleagle and Businger (1981), the saturation density of water vapor $\rho_{\mathrm{v}}\left(\mathrm{kg} \mathrm{m}^{-3}\right)$ is derived as

$\rho_{\mathrm{v}}=0.622 \cdot \frac{e_{\mathrm{S}}}{R_{\mathrm{d}} \cdot T_{\mathrm{a}}}$,

where $R_{\mathrm{d}}$ is the gas constant for dry air $\left(287 \mathrm{~J} \mathrm{~K}^{-1} \mathrm{~kg}^{-1}\right)$ and $e_{\mathrm{S}}(\mathrm{Pa})$ is the saturation vapor pressure over ice, estimated following Buck (1981) as

$e_{\mathrm{S}}=611.15 \exp \left(\frac{22.452 \cdot\left(T_{\mathrm{a}}-273.16\right)}{T_{\mathrm{a}}-0.61}\right)$.

The shortwave radiation absorbed by a snow particle with radius $r$ is defined as

$S_{\mathrm{p}}=\pi \cdot r^{2}\left(1-\alpha_{\mathrm{p}}\right) \cdot S_{\mathrm{i}}$,

where $\alpha_{\mathrm{p}}$ is the snow albedo, and $S_{\mathrm{i}}\left(\mathrm{W} \mathrm{m}^{2}\right)$ is the solar radiation at the earth's surface, which in the case of ESCIMO.spread (v2) is among the required meteorological input parameters.

To account for a melt-induced unloading of intercepted snow from the canopy, a melt-unloading rate $L_{\mathrm{m}}\left(\mathrm{kg} \mathrm{m}^{-2}\right)$ is introduced by Liston and Elder (2006b):

$L_{\mathrm{m}}=5.8 \cdot 10^{-5}\left(T_{\mathrm{a}}-273.16\right) \cdot \mathrm{d} t$.
We assume an unloading rate of $5 \mathrm{~kg} \mathrm{~m}^{-2} \mathrm{day}^{-1} \mathrm{~K}^{-1}$ whenever temperatures are above freezing, with unloading snow adding to snow accumulation at the land surface. The simulated filling and depletion of the interception storage through snowfall, sublimation and melt-induced unload is illustrated in Fig. 4 exemplarily for a period in February 2013.

\section{Data and test site description}

Snow cover simulations in this study are carried out for the forest site Vordersteinwald in the Black Forest mountain range (southwestern Germany) (see Fig. 1). This site is eminently suitable for testing of the newly developed version of ESCIMO.spread as it (i) usually experiences alternation of accumulation and melting periods over the winter season, making the simulation of snow conditions particularly demanding, and (ii) has been subject to intense snow surveys over the years 2010-present, including simultaneous observation of meteorological and snow conditions inside and outside the forest canopy (Pohl et al., 2014).

The forest stand at the study site is mostly conifer with spruce, fir and pine, representing the most common conifer tree species. To quantify the vegetation effect on snow conditions, the applied SnoMoS were installed pairwise with one SnoMoS located in the open and another set up at a close distance inside the forest canopy (see Fig. 5). The data recorded by these low-cost monitoring sensors include hourly values of snow depth, surface temperature, air temperature and humidity, global radiation, wind speed and barometric pressure.

The continuous monitoring of snow depth with the SnoMoS was accompanied by bi-weekly snow density surveys that allow translation of snow depth into SWE. A comprehensive description of the technical specifications and the instrumental setup of the SnoMoS is provided by Pohl et al. (2014). Precipitation recordings for the study site originate from nearby weather station Freudenstadt (DWD, 2015), operated by the German Weather Service (DWD). Precipitation observations have been corrected for differences in terrain elevation between the sites of measurement and model appli- 


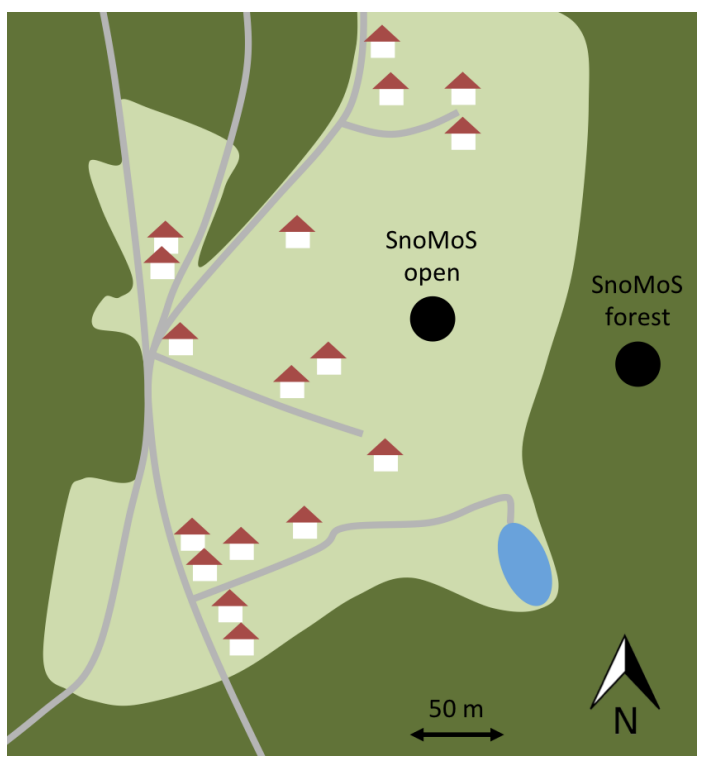

Figure 5. Schematic overview of the SnoMoS setup locations inside and outside the forest canopy at site Vordersteinwald in the Black Forest mountain range (southwestern Germany, 800 m a.s.l). The light green areas indicate grassland, the dark green areas forest, the grey lines streets and the light blue area a lake.

cation by applying monthly elevation adjustment factors as proposed by Liston and Elder (2006a). The latter have been taken from Marke (2008), who has investigated altitudinal differences in precipitation for the upper Danube watershed. No interpolation using other station data has been carried out due to the closeness of the study site ( $3 \mathrm{~km}$ distance) to station Freudenstadt. Hemispherical images were taken at the forest location and were utilized to derive the effective LAI of the forest stand $\left(\mathrm{LAI}^{*}=2.6 \mathrm{~m}^{2} \mathrm{~m}^{-2}\right)$. Moreover, a logarithmic function considering snow ageing and new snowfall was used to compute daily snow densities between the surveys. All data used as model input and for model validation are freely provided along with the model.

\section{Results}

ESCIMO.spread (v2) has been applied to modify outsidecanopy meteorological conditions for canopy effects at site Vordersteinwald as well as for a subsequent simulation of the SWE evolution for the winter season 2012/2013. Figure 6 shows outside-canopy global radiation modified for canopy effects with the new ESCIMO.spread (v2) algorithms in comparison to inside-canopy observations. As global radiation under mid-latitude prealpine conditions usually provides the largest share of energy for snowmelt, an accurate representation of inside-forest global radiation is essential for a realistic reproduction of snow ablation with any energy balance model. The general dimension and temporal variation in global radiation inside the forest canopy seem well
Table 1. Performance of ESCIMO.spread (v2) in the modification of outside-canopy global radiation, temperature, relative humidity and wind speed for canopy effects.

\begin{tabular}{lrccl}
\hline Variable & NSME & $R^{2}$ & IA & RMSE \\
\hline Global radiation & 0.64 & 0.66 & 0.89 & $8.23\left(\mathrm{~W} \mathrm{~m}^{-2}\right)$ \\
Air temperature & 0.79 & 0.82 & 0.94 & $1.74(\mathrm{~K})$ \\
Relative humidity & -1.10 & 0.61 & 0.74 & $6.31(\%)$ \\
Wind speed & -0.29 & 0.60 & 0.80 & $0.59\left(\mathrm{~m} \mathrm{~s}^{-1}\right)$ \\
\hline
\end{tabular}

reproduced with a certain tendency of the model to underestimate global radiation in the forest. The latter is also reflected by the scatterplot shown in Fig. 10 opposing simulated and observed global radiation. The satisfactory overall model performance in the modification of global radiation for canopy effects is also confirmed by the high values of the coefficient of determination $\left(R^{2}=0.66\right)$, the Nash-Sutcliffe model efficiency $(\mathrm{NSME}=0.64)$ and the index of agreement $(\mathrm{IA}=0.89)$, as well as by the low root mean square error $\left(\mathrm{RMSE}=8.23 \mathrm{~W} \mathrm{~m}^{-2}\right.$ ) (see Krause et al., 2005 for a detailed explanation of the efficiency criteria applied). The values of these efficiency criteria are provided in Table 1 with the corresponding scatterplots for the different meteorological input variables modified for canopy effects shown in Fig. 10. As shown in Fig. 7, the simulated and observed courses of temperature match fairly well until late January, whereas the simulations overestimate daily temperature peaks in spring. The efficiency criteria of $R^{2}$, NSME, IA and RMSE with values of $0.79,0.82,0.94$ and $1.74(\mathrm{~K})$, respectively, further underline the good performance of ESCIMO.spread (v2) with respect to the modification of outside-canopy temperature conditions. Compared to global radiation and temperature, the model performance for relative humidity and wind speed with $R^{2}$ and IA values on the order of 0.6 and $0.7-0.8$ for both criteria, respectively, is distinctly weaker. In the case of both variables the NSME with values below 0 indicates that the mean value of the observations would be a better predictor than the model (Krause et al., 2005). The course of relative humidity and wind speed conditions illustrated in Figs. 8 and 9 explains the diametrical picture of model performance described by means of $R^{2}$ and IA compared to NSME. While the temporal variation in relative humidity and wind speed is well reflected in the simulations (resulting in good correlation and acceptable values of $R^{2}$ and IA), the exact values in the observed time series are seldom reproduced by the model results, a condition that is considered in the calculation of NSME (Krause et al., 2005). The high temporal and spatial variability in wind speed naturally makes any spatial interpolation or modification for canopy effects particularly challenging. In the case of both variables, higher maximum values can be observed in the simulated time series.

The good overall model performance as well as the differences in model performance for the different meteoro- 


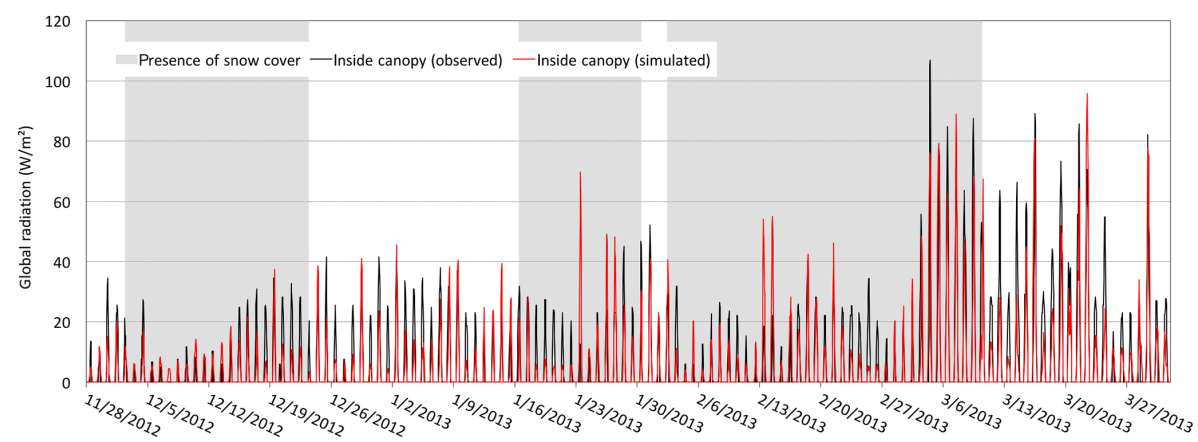

Figure 6. Simulated and observed global radiation for the winter period 2012/13 at site Vordersteinwald. The grey areas indicate periods with presence of a snow cover.

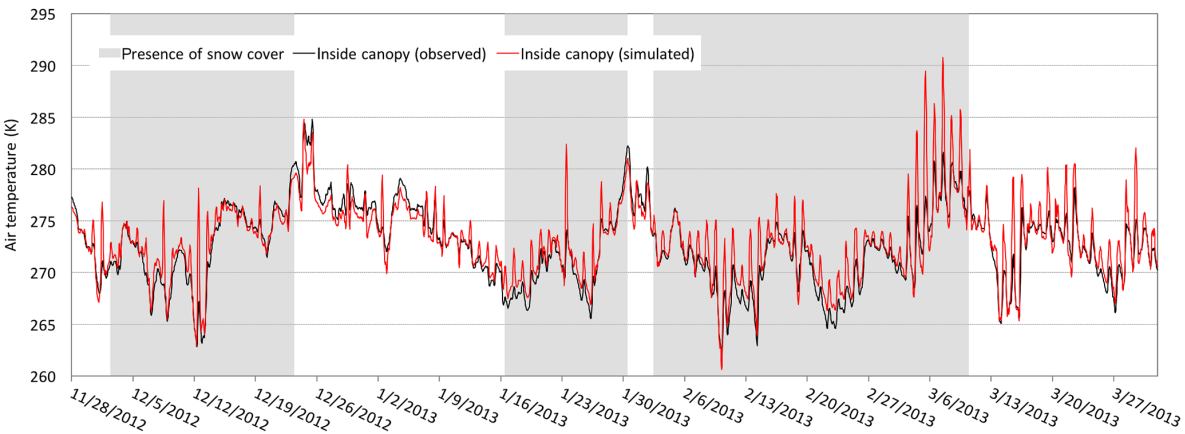

Figure 7. Simulated and observed temperature inside the forest canopy for the winter period 2012/13 at site Vordersteinwald. The grey areas indicate periods with presence of a snow cover.

logical variables might at least partly be explainable by the presence/absence of pronounced daily cycles in the hourly values. While systematic daily variations in the temperature and global radiation data can be expected to bias some efficiency criteria towards higher model performance, the lower model performance for wind speed and relative humidity might partly be due to weaker or missing daily cycles in the analyzed data. To further look into these assumptions, the predictive capabilities of outside-canopy observations for the estimation of inside-canopy conditions are provided in Table 2. Comparing the values of the different efficiency criteria calculated for the four meteorological variables to those shown in Table 1 reveals that while values of $R^{2}$ are equally high for all meteorological variables, the significant increase in NSME values clearly shows the improvements resulting from application of the canopy model, particularly when estimating global radiation inside the forest canopy. Only in the case of relative humidity do the outside-canopy measurements seem to slightly better predict inside-canopy conditions. This can be explained by the fact that, looking at the SnoMoS data for the winter season 2012/2013, measured humidity outside the canopy is often higher than that observed inside the forest stand, whereas the canopy model in ESCIMO.spread (v2) increases outside-canopy humidity
Table 2. Predictive capabilities of outside-canopy observations for inside-canopy conditions.

\begin{tabular}{lrccl}
\hline Variable & NSME & $R^{2}$ & IA & RMSE \\
\hline Global radiation & -28.24 & 0.66 & 0.39 & $73.79\left(\mathrm{~W} \mathrm{~m}^{-2}\right)$ \\
Air temperature & 0.74 & 0.85 & 0.95 & $1.92(\mathrm{~K})$ \\
Relative humidity & -0.81 & 0.65 & 0.76 & $5.84(\%)$ \\
Wind speed & -13.66 & 0.60 & 0.48 & $2.01\left(\mathrm{~m} \mathrm{~s}^{-1}\right)$ \\
SWE & -0.49 & 0.87 & 0.82 & $23.07(\mathrm{~mm})$ \\
\hline
\end{tabular}

with consideration of the canopy fraction to estimate insidecanopy relative humidity (see Eq. 21).

The simulated snow cover is displayed in Fig. 11 for the open and in Fig. 12 for inside the canopy in comparison to observations at the respective sites. As can be seen from Fig. 11, the newly developed version of ESCIMO.spread (v2) reproduces much better the observed snow conditions outside the forest at site Vordersteinwald compared to ESCIMO.spread v1. This increase in model performance is mostly due to the fact that liquid precipitation in ESCIMO.spread (v1) increases SWE by the total value of observed precipitation, whereas in the new model version, liquid precipitation is only added to the SWE up to a maximum value defined by the water holding capacity, with the 


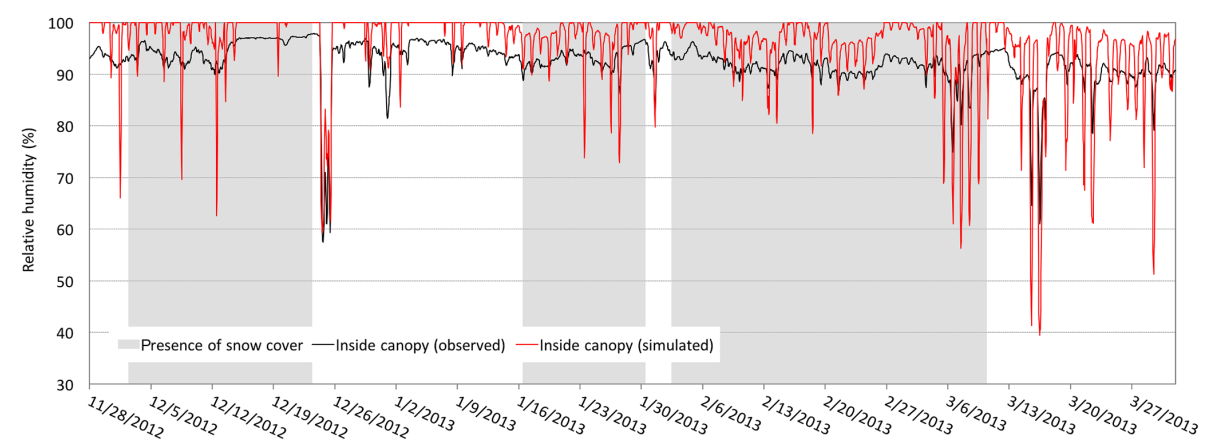

Figure 8. Simulated and observed relative humidity inside the forest canopy for the winter period 2012/13 at site Vordersteinwald. The grey areas indicate periods with presence of a snow cover.

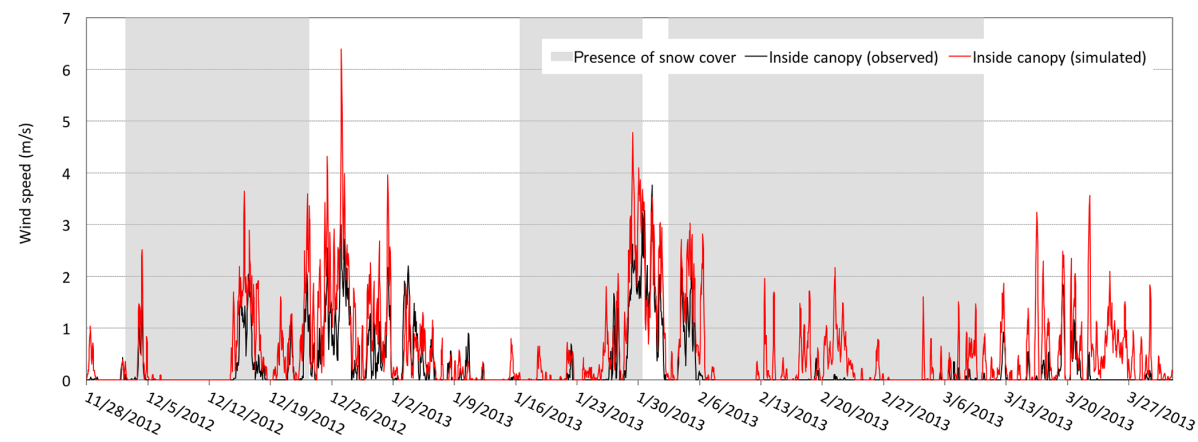

Figure 9. Simulated and observed wind speed inside the forest canopy for the winter period 2012/13 at site Vordersteinwald. The grey areas indicate periods with presence of a snow cover.

rest leaving the snowpack as outflow (see Eq. 11). While these improvements are less important for simulations at high alpine sites, where the largest share of precipitation in the winter season falls in the form of snow (see Strasser and Marke, 2010), at lower elevated sites the comparatively high amounts of liquid precipitation in winter make these model modifications essential. As a result of these further developments, the severe overestimation in simulated SWE observed in the results of ESCIMO.spread (v1) is no longer found in the results of ESCIMO.spread (v2), leading to a significant increase in model performance as confirmed by the values of the different efficiency criteria in Table 3. The simulations carried out with ESCIMO.spread (v2) sometimes even show a tendency to underestimate observed snow conditions for the winter season 2012/2013, particularly with respect to the second snow peak at site Vordersteinwald in February 2013. Looking at the results achieved for inside the canopy (see Fig. 12 and Table 3), applying the canopy model reasonably reproduces observed snow conditions inside the forest. Compared to the results achieved using observed outside-canopy snow conditions as a predictor for inside-canopy snow conditions (see Table 2), application of the proposed canopy model increases NSME values from -0.49 to 0.81 and reduces RMSE from 23.07 to $8.26 \mathrm{~mm}$.
Table 3. Performance of ESCIMO.spread v1 and ESCIMO.spread v2 at site Vordersteinwald for the winter period 2012/2013. As ESCIMO.spread v1 does not include formulations of inside-canopy processes, model performance for inside-canopy conditions is only available for ESCIMO.spread v2. The simulations inside the canopy are based on modified outside-canopy meteorological conditions.

\begin{tabular}{lrccl}
\hline Variable & NSME & $R^{2}$ & IA & RMSE \\
\hline SWE (v1) outside canopy & -15.20 & 0.34 & 0.37 & $134.28(\mathrm{~mm})$ \\
SWE (v2) outside canopy & 0.71 & 0.81 & 0.90 & $18.07(\mathrm{~mm})$ \\
SWE (v2) inside canopy & 0.81 & 0.83 & 0.95 & $8.26(\mathrm{~mm})$ \\
\hline
\end{tabular}

The fact that the model results inside the canopy are even better than for the outside (see also the scatterplots in Fig. 13) might at least partly be the result of multiple error compensation effects (including errors from precipitation measurement, the transfer of precipitation information from precipitation gauge Freudenstadt to site Vordersteinwald as well as from translating snow depth into SWE). The green line in Fig. 12 shows the simulations achieved using observed meteorological conditions inside the canopy (as provided by the SnoMoS inside the forest). Due to a lack of precipitation recordings inside the forest, the precipitation data used as input for the simulations inside the canopy in this experiment 

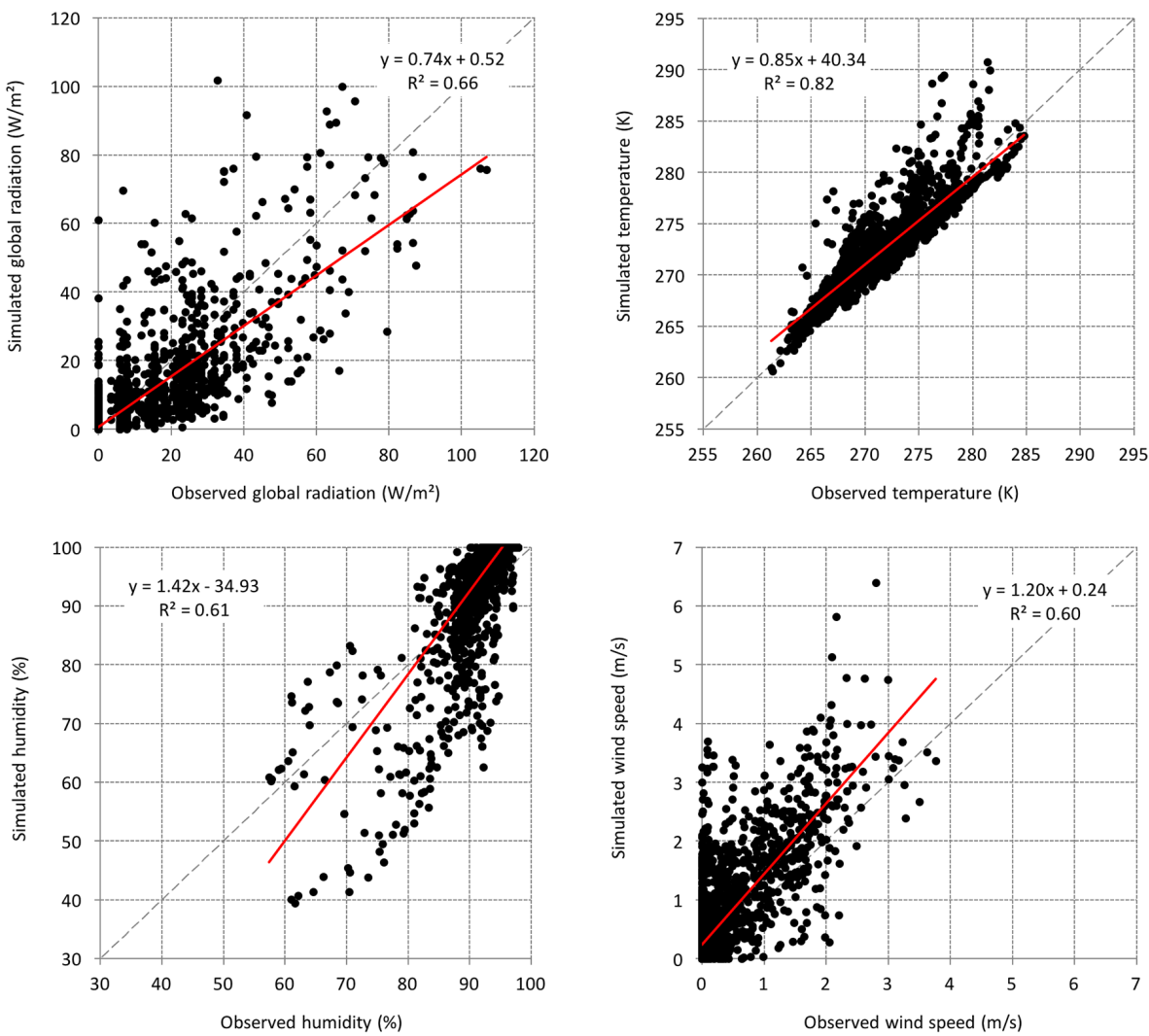

Figure 10. Simulated vs. observed meteorological conditions inside the forest canopy for the winter period 2012/13 at site Vordersteinwald.

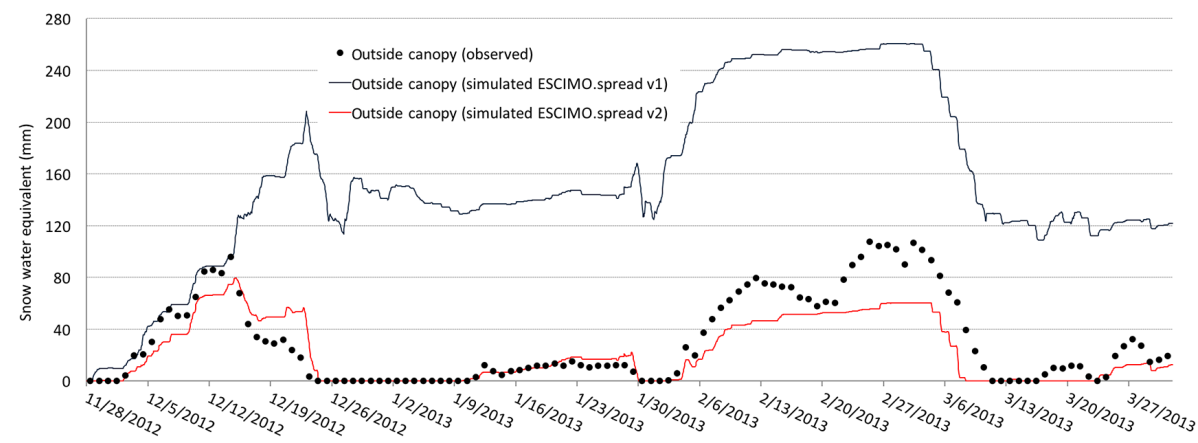

Figure 11. Simulated and observed snow water equivalent outside the forest canopy for the winter period 2012/13 at site Vordersteinwald. The blue and red lines represent the results achieved with the previous (v1) and newly developed (v2) versions of the ESCIMO.spread model, respectively.

also represent recordings from station Freudenstadt modified for canopy effects. Hence, precipitation inside the canopy as used as input for the snow simulations has to be considered a model result rather than an observation. The same applies to the incoming component of inside-canopy longwave radiation, which to a certain fraction represents the simulated top-of-canopy incoming longwave radiation due to a lack of observations outside the forest stand (see Eq. 18 and explanations below). Comparing the results achieved using observed and simulated meteorological conditions inside the forest as model input (see Fig. 12), the meteorological observations allow only slightly better model performance, with NSME increasing from 0.81 to 0.82 and RMSE decreasing from 8.26 to $8.02 \mathrm{~mm}$. The results of both model runs show a distinct overestimation of SWE between 15 and 26 December. A closer look at the conditions during this period reveals significant snowfall at temperatures close to $0{ }^{\circ} \mathrm{C}$ and air humidity close to saturation. Hence, an explanation for the observed overestimation of SWE in this period might be a false interpretation of liquid precipitation as solid precipita- 


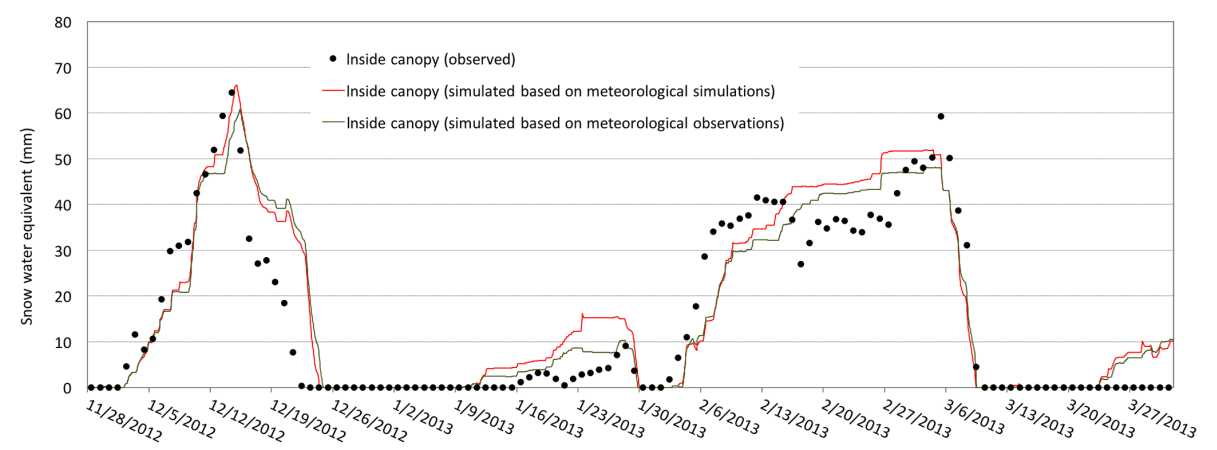

Figure 12. Simulated and observed snow water equivalent inside the forest canopy for the winter period 2012/13 at site Vordersteinwald. The two curves illustrate the snow simulations achieved with the parameterized (red) and observed (green) meteorological conditions inside the canopy.
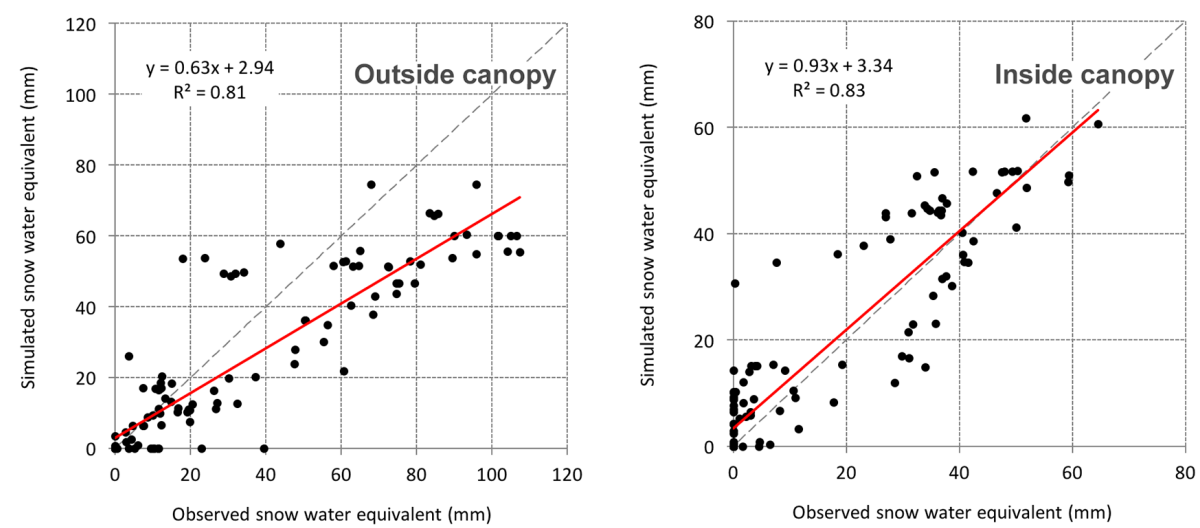

Figure 13. Snow water equivalent simulated with ESCIMO.spread (v2) vs. observed snow conditions outside and inside the forest canopy for the winter period 2012/13 at site Vordersteinwald.

tion. While the model acceptably reproduces snow accumulation between 10 and 30 January in the open, a noticeable overestimation of SWE can be observed in the results using the modified outside-canopy meteorological conditions. Moreover, a period of snow accumulation can be observed in the observations and simulations for the open in March, whereas inside the canopy this increase in SWE is merely predicted by the model and not confirmed by the observations.

\section{Conclusions}

A new version of the ESCIMO.spread spreadsheet-based point energy balance snow model has been presented (ESCIMO.spread (v2)) that allows improved precipitation phase detection, estimation of snow temperature, consideration of cold and liquid water content in the snow cover, estimation of inside-canopy meteorological conditions from meteorological observations in the open and the simulation of snow accumulation and ablation inside a forest canopy. It thereby does not require meteorological observations in the canopy, but instead derives inside-canopy meteorological conditions from available observations in the open requiring only LAI and canopy height as plant-specific input parameters. The derived meteorological conditions inside the canopy are not only applicable as input for snow cover simulations, but can also be expected to be of interest for a variety of scientific disciplines, e.g., forest ecology or pedology. To provide the data required for model application and evaluation, a pair of SnoMoS have been utilized as an innovative technology that allows the collection of important meteorological variables at low financial costs. Comparison of simulated insidecanopy meteorological conditions to observations at a site in the Black Forest region (Germany) reveals good overall model performance, particularly with respect to global radiation $\left(\mathrm{NSME}=0.64 \mathrm{~W} \mathrm{~m}^{-2}, \mathrm{RMSE}=8.23 \mathrm{~W} \mathrm{~m}^{-2}\right)$ and temperature $(\mathrm{NSME}=0.79 \mathrm{~K}, \mathrm{RMSE}=1.74 \mathrm{~K})$, representing the most important meteorological variables for the estimation of snowmelt. In the case of relative humidity and wind speed, the model efficiency with NSME values of -1.10 and -0.29 and an RMSE of $6.31 \%$ and $0.59 \mathrm{~m} \mathrm{~s}^{-1}$ for the two variables, respectively, was noticeably lower. This lower model performance might at least partly be the result of weaker or missing daily cycles in the hourly data as well 
as potential biases in the measurements of the applied lowcost monitoring systems, which are described in detail by Pohl et al. (2014). A satisfactory model performance unfolds when comparing the simulated snow cover evolution inside and outside the canopy to snow observations provided by the SnoMoS. NSME here reaches values of 0.81 and 0.71 with an RMSE of 8.26 and $18.07 \mathrm{~mm}$ for simulated SWE inside and outside the canopy, respectively. While snow cover evolution is well reproduced for both, outside and inside the forest canopy, model performance is slightly higher for inside-canopy conditions, even though the empirical model parameters have not yet been adjusted to (pre)alpine forest species. This might at least partly be explainable by multiple error compensation effects (including errors from precipitation measurement, the transfer of precipitation information from precipitation gauge Freudenstadt to site Vordersteinwald and the translation from snow depth to SWE). To further improve the implemented parameterization of insidecanopy processes, the simultaneous observations of snow and meteorological conditions as provided by the SnoMoS are currently used to develop model parameters that are tailored to the specific conditions in (pre)alpine forests.

Despite its physically based character and advanced model features, ESCIMO.spread (v2) still oversimplifies some important processes of the snow-vegetation interaction. In the current version, the model only considers unloading of intercepted snow as a result of melting. While the fact that wind also induces unloading of intercepted snow is well known, the combined dependence on plant characteristics (e.g., plant structure and plant element flexibility) and meteorological conditions (e.g., snow temperature, wind speed and direction) makes this a complex process hard to consider in numerical models (Liston and Elder, 2006b). The modification of shortwave and longwave radiation assumes a plantspecific extinction coefficient and a constant canopy fraction, respectively. While these assumptions can be expected to reasonably reproduce the general observed patterns in local radiation, they are not capable of accurately capturing the actual radiation conditions whenever canopy densities strongly vary or sunlight is shining through open areas in the trees as a result of changing solar zenith angles.

\section{Code availability}

ESCIMO.spread (v2) can be downloaded free of charge at www.alpinehydroclimatology.net together with 1 year of sample data including the meteorological and snow observations used in this study. The model has been tested on OpenOffice 4.1.1 as well as on different versions of Microsoft Excel for Windows and Mac.

Acknowledgements. The authors thank the Austrian Climate and Energy Fund for the financial support of the presented research (ACRP6 - STELLA - KR13AC6K11109) within the Austrian Climate Research Programme. Moreover, we thank the German
Weather Service (DWD) for the provision of the precipitation recordings at station Freudenstadt.

Edited by: J. Neal

\section{References}

Blöschl, G. and Kirnbauer, R.: Point snowmelt models with different degrees of complexity - internal processes, J. Hydrol., 129, 127-147, 1991.

Braun, L. N.: Simulation of Snowmelt-Runoff in Lowland and Lower Alpine Regions of Switzerland, PhD thesis, ETH Zurich, Zürich, 1984.

Breuer, L., Eckhardt, K., and Frede, H.-G.: Plant parameter values for models in temperate climates, Ecol. Model., 169, 237-293, 2003.

Brock, B. W. and Arnold, N. S.: A spreadsheet-based (Microsoft Excel) point surface energy balance model for glacier and snow melt studies, Earth Surf. Proc. Land., 25, 649-658, 2000.

Buck, A. L.: New equations for computing vapor pressure and enhancement factor, J. Appl. Meteorol., 20, 1527-1532, 1981.

Campbell, G. S. and Norman, J. M.: An Introduction to Environmental Biophysics, Springer, New York, 1998.

Chen, J. M., Rich, P. M., Gower, S. T., Norman, J. M., and Plummer, S.: Leaf area index of boreal forests: theory, techniques, and measurements, J. Geophys. Res., 102, 29429-29443, doi:10.1029/97JD01107, 1997.

Cionco, R. M.: Analysis of canopy index values for various canopy densities, Bound.-Lay. Meteorol., 15, 81-93, 1978.

Dickerson-Lange, S. E., Lutz, J. A., Martin, K. A., Raleigh, M. S., Gersonde, R., and Lundquist, J. D.: Evaluating observational methods to quantify snow duration under diverse forest canopies, Water Resour. Res., 51, 1203-1224, doi:10.1002/2014WR015744, 2015.

Durot, K.: Modélisation hydrologique distribuée du bassin versant nivo-pluvial de Sarennes, Validation des données d'entrée et dévelopement d'un module de fonte nivale sous forêt, $\mathrm{PhD}$ thesis, LTHE, Grenoble, 1999.

DWD: Precipiatation Dataset from Station Freudenstadt, German Weather Service (DWD), Offenbach am Main, available at: ftp://ftp-cdc.dwd.de/pub/CDC/observations_germany/ climate/hourly/, last access: 18 September 2015.

Essery, R., Pomeroy, J., Parviainen, J., and Storck, P.: Sublimation of snow from coniferous forests in a climate model, J. Climate, 16, 1855-1864, 2003.

Fleagle, R. G. and Businger, J. A.: An Introduction to Atmospheric Physics, 2 edn., Cambridge University Press, Cambridge, 1981.

Hardy, J. P., Melloh, R., Robinson, P., and Jordan, R.: Incorporating effects of forest litter in a snow process model, Hydrol. Process., 14, 3227-3237, 2001.

Hedstrom, N. R. and Pomeroy, J. W.: Measurements and modelling of snow interception in the boreal forest, Hydrol. Process., 12, 1611-1625, 1998.

Hellström, R.: Forest cover algorithms for estimating meteorological forcing in a numerical snow model, Hydrol. Process., 14, 3239-3256, 2001.

Kraus, H.: Die Atmosphäre der Erde - eine Einführung in die Meteorologie, Springer, Heidelberg, 2004. 
Krause, P., Boyle, D. P., and Bäse, F.: Comparison of different efficiency criteria for hydrological model assessment, Adv. Geosci., 5, 89-97, doi:10.5194/adgeo-5-89-2005, 2005.

Link, T. and Marks, D.: Distributed simulation of snowcover massand energy-balance in the boreal forest, Hydrol. Process., 13, 2439-2452, 1999a.

Link, T. E. and Marks, D.: Point simulation of seasonal snow cover dynamics beneath boreal forest canopies, J. Geophys. Res., 104, 27841-27857, doi:10.1029/1998JD200121, 1999b.

Liston, G. E. and Elder, K.: A meteorological distribution system for high-resolution terrestrial modeling (MicroMet), J. Hydrometeorol., 7, 217-234, 2006a.

Liston, G. E. and Elder, K.: A distributed snow-evolution modeling system (SnowModel), J. Hydrometeorol., 7, 1259-1276, $2006 \mathrm{~b}$.

Marke, T.: Development and Application of a Model Interface to Couple Land Surface Models with Regional Climate Models for Climate Change Risk Assessment in the Upper Danube Watershed, PhD thesis, Ludwig-Maximilians-University, Munich, 2008.

Marsh, P.: Snowcover formation and melt: recent advances and future prospects, Hydrol. Process., 13, 2117-2134, 1999.

Melloh, R. A., Hardy, J. P., Davis, R. E., and Robinson, P. B.: Spectral albedo/reflectance of littered forest snow during the melt season, Hydrol. Process., 15, 3409-3422, 2002.

Montesi, J., Elder, K., Schmidt, R. A., and Davis, R. E.: Sublimation of intercepted snow within a subalpine forest canopy at two elevations, J. Hydrometeorol., 5, 763-773, doi:10.1175/15257541(2004)005<0763:SOISWA>2.0.CO;2, 2004.

Obled, C.: Modèles mathématiques de la fusion nivale, $\mathrm{PhD}$ thesis, Université Scientifique et Médicale de Grenoble, Grenoble, 1971.

Pohl, S., Garvelmann, J., Wawerla, J., and Weiler, M.: Potential of a low-cost sensor network to understand the spatial and temporal dynamics of a mountain snow cover, Water Resour. Res., 50, 2533-2550, 2014.

Pomeroy, J. and Gray, D. M.: Snowcover: Accumulation, Relocation, and Management, Tech. Rep. 7, National Hydrology Research Institute, National Hydrology Research Institute Science Report No. 7, Saskatoon, Canada, 1995.
Pomeroy, J. W., Parviainen, J., Hedstrom, N., and Gray, D. M.: Coupled modelling of forest snow interception and sublimation, Hydrol. Process., 12, 2317-2337, 1998.

Pomeroy, J. W., Gray, D. M., Hedstrom, N. R., and Janowicz, J. R.: Prediction of seasonal snow accumulation in cold climate forests, Hydrol. Process., 16, 3543-3558, 2002.

Schmidt, R. A.: Sublimation of Wind-Transported Snow: a Model, Tech. rep., USDA Forest Service research paper, Rocky Mountain Forest and Range Experiment Station, Fort Collins, CO, 1972.

Steinacker, R.: Diagnose und Prognose der Schneefallgrenze, Wetter und Leben, 35, 81-90, 1983.

Strasser, U.: Modelling of the mountain snow cover in the Berchtesgaden National Park, Forschungsberichte des Nationalpark Berchtesgaden, 55, 1-184, 2008.

Strasser, U. and Marke, T.: ESCIMO.spread - a spreadsheetbased point snow surface energy balance model to calculate hourly snow water equivalent and melt rates for historical and changing climate conditions, Geosci. Model Dev., 3, 643-652, doi:10.5194/gmd-3-643-2010, 2010.

Strasser, U., Bernhardt, M., Weber, M., Liston, G. E., and Mauser, W.: Is snow sublimation important in the alpine water balance?, The Cryosphere, 2, 53-66, doi:10.5194/tc-2-53-2008, 2008.

Strasser, U., Warscher, M., and Liston, G. E.: Modeling snow canopy processes on an idealized mountain, J. Hydrometeorol. 12, 663-677, 2011.

Thorpe, A. D. and Mason, B. J.: The evaporation of ice spheres and ice crystals, Briti. J. Appl. Phys., 17, 541-548, 1966.

Walter, M. T., Brooks, E. S., McCool, D. K., King, L. G., Molnau, M., and Boll, J.: Process-based snowmelt modeling: does it require more input data than temperature-index modeling?, J. Hydrol., 300, 65-75, 2005. 